\title{
A Experimentação na Formação Inicial de Professores de Ciências e Biologia
}

\author{
Experimentation in the Initial Training of Science and Biology Teachers
}

\author{
Ynaiara Kristhine Stopa da Cruz; ; Victor Angelo Primo Bernardes ${ }^{\mathrm{b}}$; Rodrigo de Souza Poletto ${ }^{\mathrm{a}}$
}

${ }^{a}$ Universidade Estadual do Norte do Paraná, Programa de Pós-Graduação Stricto Sensu em Ensino. PR, Brasil.

bUniversidade Estadual do Norte do Paraná, PR, Brasil

*E-mail: ynaiara_stopa@hotmail.com

\begin{abstract}
Resumo
Atividades práticas contribuem para maior participação dos estudantes nas disciplinas, auxilia a despertar o interesse pelo conteúdo, além de contribuir na compreensão e construção do conhecimento científico. Desse modo, a presente pesquisa teve como objetivo elaborar uma experimentação científica, a fim de auxiliar os estudantes de um curso de licenciatura em Ciências Biológicas para maior compreensão a respeito do conteúdo de metabólitos secundários - alelopatia, assim como analisar a contribuição de tal estratégia. Desse modo, utilizou-se como instrumento de coleta de dados, os relatos contidos nas sínteses avaliativas respondidas pelos estudantes. A análise dos resultados foi embasada pelo referencial teórico da Análise Textual Discursiva. Os resultados da experimentação apresentaram indícios de que a estratégia utilizada despertou interesse nos estudantes, possibilitando momentos de aprendizagem. Assim como, contribuiu para formação inicial destes futuros professores, pois permitiu que os licenciandos mobilizassem saberes docentes, como os disciplinares, pedagógicos e experienciais. Quando se evidência essa mobilização de saberes, é possível ter indícios de que os licenciandos possivelmente possuirão pré-requisitos para preparar aulas no modelo didático aplicado. Um dos desdobramentos dessa pesquisa é motivar pesquisadores da área de ensino a voltar suas pesquisas para formação de professores, na perspectiva de prepará-los para empregar diferentes estratégias didáticas no Ensino de Ciências e Biologia.
\end{abstract}

Palavras Chave: Formação de Professores. Aulas Práticas. Atividades Experimentais. Ensino de Ciências.

\begin{abstract}
Abstrat
Practical activities contribute to greater participation of students in the disciplines, helps to arouse interest in content, besides contributing to the understanding and construction of scientific knowledge. Thus, the present research aimed to elaborate a scientific experiment, in order to assist students of a degree course in Biological Sciences to better understand the content of secondary metabolites - allelopathy, as well as analyzing the contribution of such a strategy. Thus, the reports contained in the evaluative syntheses answered by the students were used as data collection instrument. The analysis of the results was based on the theoretical framework of Discursive Textual Analysis. The results of the experiment showed evidence that the strategy used aroused interest in students, enabling learning moments. As well as, it contributed to the initial formation of these future teachers, because it allowed the graduates to mobilize teaching knowledge, such as disciplinary, pedagogical and experiential. When this mobilization of knowledge is evidenced, it is possible to have indications that the undergraduates may have prerequisites to prepare classes in the applied didactic model. One of the developments of this research is to motivate researchers in the teaching area to return their research to teacher education, in order to prepare them to employ different didactic strategies in science and biology teaching.
\end{abstract}

Keywords: Teacher training. Practical classes. Experimental Activities. Science Teaching.

\section{Introdução}

O uso de atividades práticas desperta a motivação e estímulo dos estudantes (FALA; CORREIA; PEREIRA; 2010). Santos (2009) em sua pesquisa sobre Física no Ensino Médio, demostra que a atividade experimental gerou maior interesse de participação dos estudantes e maior motivação a participar do desenvolvimento da disciplina. A motivação por si só não garante aprendizagem, no entanto é um importante passo para que ela ocorra efetivamente.

Para o ensino de Biologia, é necessário utilizar de diversas estratégias para consolidar o processo de Ensino e Aprendizagem, e as atividades experimentais são ferramentas pedagógicas tão relevantes quanto o planejamento, aulas bem elaboradas e docentes bem preparados e fundamentados teoricamente (DELIZOICOV; ANGOTTI; PERNAMBUCO, 2009; MARANDINO, SELLES; FERREIRA, 2009; SANTOS, 2008, 2009; FALA; CORREIA; PEREIRA; 2010).

A experimentação pode contribuir para aproximação do ensino de Ciências das características do trabalho científico, para contribuição do conhecimento e desenvolvimento intelectual dos estudantes (MARANDINO; SELLES; FERREIRA, 2009), a pesquisa em sala de aula favorece a construção do conhecimento profissional do futuro professor (GALIAZZI; GONÇALVES, 2004).

Aulas práticas desempenham funções importantes nos cursos de Ciências Biologias, pois permitem que os 
alunos tenham contato direto com fenômenos, manipulem materiais e observem organismos. Em aulas práticas os estudantes enfrentam os resultados não previstos, e a interpretação desafiam seu raciocínio e imaginação, despertam o interesse, desenvolve a capacidade de resolver problemas (KRASILCHIK, 2004). Segundo Thomaz (2000), a experimentação auxilia na aprendizagem dos conteúdos científicos, assim como desenvolver as capacidades científicas dos alunos para atuarem de maneira efetiva após sua formação acadêmica.

A prática docente requer saberes e conhecimentos científicos, pedagógicos educacionais, e também sensibilidade, indagação teórica e criatividade para enfrentar os desafios do Ensino, o docente necessita também de sensibilidade, ética e consciência política (DELIZOICOV; ANGOTTI; PERNANBUCO, 2009). "E da natureza da atividade docente proceder à medicação reflexiva e crítica entre as transformações sociais e a formação humana dos estudantes, questionando, os modos de pensar, sentir, agir e produzir e distribuir conhecimentos" (DELIZOICOV; ANGOTTI; PERNANBUCO, 2009, p.15).

Diversos saberes, obtidos de diferentes fontes, desde a formação inicial e/ou continuada, como os saberes disciplinares, curriculares e pedagógicos, até os saberes experienciais, adquiridos ao longo do cotidiano do professor a partir de suas experiências enquanto aluno e docente mobilizam a prática docente (PIMENTA, 2012; GAUTHIER et al, 2013; TARDIF, 2014).

Nas ciências naturais, para favorecer a aprendizagem dos estudantes é preciso de conhecimentos diversos para uma boa prática docente. Porém, as disciplinas de Ciências e Biologia ao longo da história foram marcadas por muitas críticas em relação a um ensino voltado para memorização e descrição, baseada em aulas e avaliações pouco significativas para que os estudantes possam realizem conexões além dos conhecimentos biológicos (MARANDINO; SELLES; FERREIRA, 2009). Desse modo, para que o ensino possa ser efetivo é relevante que as abordagens metodológicas durante as aulas despertem a motivação e interesse dos alunos.

Entre as modalidades didáticas que podem ser utilizadas a prática docente, a experimentação é uma metodologia de ensino de grande importância, pois possibilita o aluno a aprender conceitos científicos por meio da reflexão crítica e da investigação, além de ser um motivador da aprendizagem, levando ao desenvolvimento de habilidades técnicas e principalmente auxiliando a fixação e o conhecimento sobre fenômenos e fatos (KRASILCHIK, 2004).

Para Delizoicov, Angotti e Pernambuco (2009) o ensino com o uso da experimentação, é considerado por muitos professores, como importante para o bom desenvolvimento da aprendizagem dos seus alunos. No entanto, para que a experimentação possa vir a acontecer, é fundamental que o professor tenha familiaridade com a experimentação e crie expectativas relativas a esta metodologia.

As atividades experimentais são um instrumento didático valioso, pois permite ao docente enriquecer suas aulas, utilizando-as para diversas situações. Oliveira (2010) aponta algumas contribuições das atividades experimentais, no Ensino e Aprendizagem de Ciências: 1. motivar e despertar a atenção dos alunos; 2. desenvolver a capacidade de trabalhar em grupo; 3. desenvolver a iniciativa pessoal e a tomada de decisão; 4. estimular a criatividade; 5 . aprimorar a capacidade de observação e registro de informações; 6. aprender a analisar dados e propor hipóteses para os fenômenos; 7. aprender conceitos científicos; 8. detectar e corrigir erros conceituais dos alunos; 9. compreender a natureza da ciência e o papel do cientista em uma investigação; 10. compreender as relações entre ciência, tecnologia e sociedade; 11. aprimorar habilidades manipulativas.

Nesse sentido, as aulas experimentais podem ser empregadas com diferentes objetivos fornecendo variadas e importantes contribuições no ensino e aprendizagem.

Portanto o objetivo dessa pesquisa foi elaborar uma experimentação científica, a fim de auxiliar os estudantes de um curso de licenciatura em Ciências Biológicas para melhor compreensão a respeito do conteúdo de metabólitos secundários - alelopatia, assim como analisar as percepções dos futuros professores e as a contribuição de tal estratégia.

\section{Material e Métodos}

Previamente a aula prática os alunos tiveram algumas aulas sobre metabólitos secundários, onde foi desenvolvida a parte teórica, assim esse experimento teve como objetivo complementar essas aulas para melhor compreensão do conteúdo. Na primeira semana os alunos montaram o experimento que foi desenvolvido no laboratório de uma Universidade Pública do Paraná e uma semana depois realizaram a análise dos resultados do experimento.

O conteúdo utilizado para elaboração da prática foi de Metabólitos Secundários - Alelopatia para qual foi utilizado como base o referencial de Taiz e Zeiger (2013) e Ferreira; Borghetti (2004).

A prática foi realizada no Laboratório Interdisciplinar de Pesquisa e Ensino de Botânica e Educação Ambiental (LIPEBEA) da Universidade Estadual do Norte do Paraná, pelos licenciandos de Ciências Biológicas. Foram produzidos extratos a partir de folhas de Mimosa ramosissima (dormideira), coletadas no campo e secas em estufa de secagem e esterilização á 40 graus por 24 horas. Como planta teste utilizou-se sementes de Cucumis sativus (pepino) e Megathyrus maximus cv aruana (capim aruana). Para confecção do extrato foi utilizado $40 \mathrm{~g}$ de folhas secas, aos quais foi adicionado $400 \mathrm{ml}$ água destilada, bate-se o material no liquidificador, filtrou em tecido de algodão, e em seguida diluiu a concentração de $30 \%$, sendo $24 \mathrm{ml}$ de extrato e $56 \mathrm{ml}$ de água destilada. Com a finalidade de se verificar o efeito 
desses extratos na germinação e desenvolvimento inicial de sementes de Cucumis sativus (pepino) e de Megathyrus maximus (Capim aruana) a turma foi dividida em 6 grupos onde cada grupo ficou com um tratamento, já estava sobre a bancada todo material que os grupos iriam precisar para realização do experimento.

$\mathrm{Na}$ primeira bancada foram dispostos dois grupos, um com sementes Cucumis sativus que foi identificado como Pepino Controle (PC, e outro grupo com sementes de Megathyrus maximus, identificado como Aruana Controle (AC), e solução de $80 \mathrm{ml}$ de água destilada para cada grupo. $\mathrm{Na}$ segunda bancada, outros dois grupos estavam dispostos um com sementes Cucumis sativus, que foi identificado como P30\%, e outro grupo com sementes de Megathyrus maximus, identificado como A30\%, e a solução de $80 \mathrm{ml}$ de extrato de Mimosa ramosissima a 30\% respectivamente. Na terceira bancada, estavam os grupos do Pepino (P100\%) e do Aruana (A100\%), no qual a solução era de $80 \mathrm{ml}$ de extrato $100 \%$.

Os grupos separam com auxilio de uma pinça 15 sementes em cada placa de Petri contendo papel filtro, mediram 15 $\mathrm{ml}$ das soluções para cada placa, respectiva ao tratamento, o com auxilio de um medidor, após identificar as placas, elas foram acondicionadas em câmara de germinação a $25^{\circ} \mathrm{C}$ e luz constante, ao final da aula os alunos realizaram uma síntese avaliativa sobre a prática.

Após 7 dias, os estudantes mediram o crescimento das partes aéreas e radicular das plântulas e calcularam a média de germinação, crescimento radicular e crescimento parte aérea.

Para a análise destes resultados, deve-se levar em consideração que as sementes de capim aruana levam em média 10 dias para germinar, sendo assim, como o experimento levou em consideração apenas 7 dias, não podemos tirar análises consideráveis destas sementes. Já as sementes de pepino deixam evidente que a em baixas concentrações $(30 \%)$ o extrato de Mimosa ramosissima tem ação estimulante na germinação das sementes, já em altas concentrações (100\%) o extrato tem ação negativa, interferindo na germinação. Assim os estudantes puderam observar que o potencial alelopático da Mimosa ramosissima possui interferência tanto na germinação quanto no crescimento da raiz e parte aérea, e que em altas concentrações interrompem o processo germinativo. Ao final da aula os licenciandos responderam uma síntese avaliativa sobre a aula.

\subsection{Encaminhamentos metodológicos}

A pesquisa apresentada neste trabalho é parte integrante de uma sequência didática, a qual foi elaborada e aplicada em um curso de licenciatura em Ciências Biológicas, para estudantes do $4^{\mathrm{a}}$ ano na disciplina de Fisiologia Vegetal. Os participantes da pesquisa foram 26 licenciandos, que possuíam idade entre vinte e trinta anos, sendo 16 do sexo feminino e 10 do sexo masculino. Por uma questão ética, para análise dos dados os estudantes foram codificados pela letra L, seguido de um número ordinal: L1, L2, L3, L4..., L26.
Como instrumento de coleta de dados da participação da aula prática, utilizamos os relatos contidos nas sínteses avaliativas, que de acordo com Barbosa, (2017) tem como objetivo "fazer com que os alunos revelem suas facilidades, dificuldades e que o façam refletir a respeito do encontro realizado, se foi produtivo, o que chamou mais atenção e o que pode ser melhorado", além de auxiliar o docente a adaptar as atividades para um próximo encontro. Para seleção dos estudantes para análise dos dados da pesquisa, utilizamos os critérios de diversidade e saturação. Em relação à diversidade, ponderamos o critério da diversificação interna (GUERRA, 2006), que nos possibilita uma exploração a respeito da diversidade de opiniões de um determinado grupo, no nosso caso estudantes do quarto ano do curso de Ciências Biológicas de uma Universidade Pública do Paraná. Para o critério de saturação, aplicamos os preceitos de Pires (1997, p. 157), que "permite generalizar os resultados ao universo do trabalho (população) a que o grupo analisado pertence (generalização empírico-analítica)". Desse modo foram selecionadas as atividades desenvolvidas pelos estudantes com a finalidade de assegurar que eles formassem um grupo representativo (proporcional) dos demais estudantes.

Para análise dos dados a partir das respostas dos estudantes, utilizamos como base o referencial teórico da Análise Textual Discursiva - ATD (MORAES, 2003; MORAES; GALIAZZI, 2014).

A ATD tende a obter compreensões reconstruídas dos discursos, conduzindo a uma comunicação do aprendido. Realizando processo de desconstrução, seguido da reconstrução de um conjunto de materiais linguísticos e discursivos, por meio de textos diversos, amostras de discursos, denominados corpus (MORAES, 2003).

A abordagem de análise qualitativa é organizada em torno de quatro focos. O primeiro é a desmontagem dos textos, também denominado de processo de unitarização; o segundo é o estabelecimento de relações, processo denominado de categorização; o terceiro é captação do novo emergente, que resulta na produção de um metatexto a partir do processo de compreensão alterada do todo; e o quarto constitui um processo auto-organizado. Os três primeiros compõem um ciclo no qual se constituem como elementos principais (MORAES, 2003; MORAES; GALIAZZI, 2014).

Assim, as respostas dadas pelos licenciandos nas atividades formaram o corpus de análise, os quais formaram as categorias Categoria 1 - Efeito motivador das atividades experimentais; Categoria 2 - Contribuições da estratégia de ensino, para analisarmos de que maneira o experimento contribuiu para conhecimento científico de alelopatia.

\section{Resultados e Discussão}

Odesenvolvimento da atividade iniciou-secoma explicação do desenvolvimento do experimento, tecemos orientações para montagem, os estudantes puderam tirar dúvidas, gerando assim um diálogo interativo onde o conhecimento previamente 
construído e o conhecimento científico que foi moldado no ambiente de sala de aula. O diálogo facilita o desenvolvimento cognitivo dos estudantes, e contribui para aprendizagem do conteúdo a partir da construção de novos conceitos coerentes aos conceitos científicos (ARAÚJO, 2011). Partindo de que o ensino de Biologia deva ser direcionado ao desenvolvimento de competências que permitam aos estudantes lidar com os conhecimentos, compreendê-los, reelaborá-los, refutá-los, e assim compreender o mundo e nele agir com autonomia, fazendo uso dos conhecimentos adquiridos da Biologia, deixamos os estudantes livres para conduzir seu experimento.

Ao final da montagem do experimento os licenciandos responderam uma síntese avaliativa, e na aula de análise dos resultados do experimento realizaram outra síntese avaliativa, as respostas dessas sínteses foram analisadas a luz, da análise textual discursiva (ATD). Para análise dos dados elencamos as seguintes categorias: Categoria 1 - Efeito motivador das atividades experimentais; Categoria 2 - Contribuições da estratégia de ensino. Nesse sentido, apresenta-se no Quadro 1 , alguns excertos, que demostram o efeito motivador das atividades experimentais.

Quadro 1- Categoria 1 - Efeito motivador das atividades

\begin{tabular}{|l|l|}
\hline \multicolumn{1}{|c|}{ Unidades } & \multicolumn{1}{c|}{ Excertos } \\
\hline & $\begin{array}{l}\text { "Essa aula foi muito interessante, pois o } \\
\text { tema de fato é muito legal, estou ansiosa } \\
\text { para saber os resultados" (L18, A1) } \\
\text { "A aula foi bem interessante e despertou a } \\
\text { Houve } \\
\text { motivação } \\
\text { ficamos curiosos para saber o resultado do } \\
\text { experimento" (L25, A1). } \\
\text { "A aula foi interessante, pois foram } \\
\text { utilizados métodos práticos saindo um } \\
\text { pouco da rotina do teórico" (L6, A1). }\end{array}$ \\
\hline NÃO HOUVE \\
MOTIVAÇÃO
\end{tabular} \mid \begin{tabular}{l}
----------- \\
\hline
\end{tabular}

Conforme observado nos excertos, a utilização de atividades experimentais contribui para motivar os estudantes e desparta curiosidade. Os estudantes apontam que "a aula foi interessante, pois foram utilizados métodos práticos saindo um pouco da rotina do teórico" (L6, A1), "essa aula foi muito interessante, pois o tema de fato é muito legal, estou ansiosa para saber os resultados" (L18, A1).

A motivação por si só não garante aprendizagem, mas é um importante passo para que ela ocorra efetivamente. Santos (2009) em sua pesquisa fala que aulas práticas não devem ter como único objetivo a motivação e nem ver nelas a solução para todos os tipos de problemas relativos ao ensino e aprendizagem, mas que devem ser utilizadas com objetivos bem definidos e não perder o caráter de aprimorar os conhecimentos dos estudantes.

Em complemento Vieira, Bianconi e Dias (2005, p.23) afirmam que "a questão metodológica, a abordagem de temas e conteúdos apresentados por meio de diferentes recursos, e as estratégias e dinâmicas, podem contribuir para o aprendizado".
Segundo Galiazzi e Gonçalves (2004), as atividades experimentais são intrinsecamente motivadoras e contribuem para captar jovens cientistas, pois por meio da experimentação em sala de aula se valida e comprova uma teoria.

A partir da fala dos estudantes, podemos delinear algumas contribuições da estratégia de ensino (Quadro 2).

Quadro 2 - Categoria 2 - Contribuições da estratégia de ensino

\begin{tabular}{|c|c|}
\hline Unidades & Excertos \\
\hline $\begin{array}{l}\text { HOUVE } \\
\text { CONTRIBUIÇÃO }\end{array}$ & $\begin{array}{l}\text { Com aula prática pude associar o } \\
\text { conteúdo teórico e ter uma melhor } \\
\text { compreensão. (L18, A1). } \\
\text { O procedimento da aula prática } \\
\text { ocorreu de maneira significativa, } \\
\text { pois esclareceu muitas dúvidas que } \\
\text { tinha. (L24, A1). } \\
\text { A aula pratica agrega o conhecimento } \\
\text { da teoria o que facilita o entendimento } \\
\text { do tema. (L25, A1). } \\
\text { Muito boa à aula, relembrar essas } \\
\text { práticas é sempre bom para fixação } \\
\text { dos métodos. (L16, A1). } \\
\text { Foi muito boa à aula, pois consegui } \\
\text { entender os efeitos alelopático. (L13, } \\
\text { A1). }\end{array}$ \\
\hline $\begin{array}{l}\text { CONTRIBUIÇÃO } \\
\text { DAS ANÁLISES DOS } \\
\text { RESULTADOS }\end{array}$ & $\begin{array}{l}\text { A aula foi dinâmica e observamos as } \\
\text { sementes que germinaram e através } \\
\text { da análise dos dados, verificamos o } \\
\text { efeito alelopático sobre as sementes } \\
\text { (L25, A2). } \\
\text { Foi extremamente importante } \\
\text { observar os resultados da aula prática, } \\
\text { o que facilitou o entendimento da } \\
\text { realização do experimento (L25, } \\
\text { A2). } \\
\text { Foi uma boa experiência prática de } \\
\text { alelopatia e análise dos efeitos dos } \\
\text { compostos secundários (L16, A2). } \\
\text { Aprendi com os resultados da } \\
\text { aula prática a ação dos extratos na } \\
\text { germinação de sementes (L6,A2). } \\
\text { [...] podemos através dessa aula } \\
\text { compreender melhor como funciona } \\
\text { um alelopático. (L18, A2) } \\
\text { A aula foi de extrema importância } \\
\text { para compreendermos o efeito da } \\
\text { alelopatia por meio dos resultados } \\
\text { obtidos no experimento. (L24, A2). }\end{array}$ \\
\hline
\end{tabular}

A partir da análise dos excertos dos estudantes, podemos observar que a opinião emitida por eles sugere uma valorização da estratégia utilizada. Os licenciandos apontam que a atividade experimental foi uma estratégia que "agrega o conhecimento da teoria o que facilita o entendimento do tema” (L25, A1); “o procedimento da aula prática ocorreu de maneira significativa, pois esclareceu muitas dúvidas que tinha” (L24, A1); “com aula prática pude associar o conteúdo teórico e ter uma melhor compreensão" (L18, A1).

Podemos observar nas falas não apenas a visão de estudantes que participaram de uma atividade experimental, mas também a visão de futuros professores, visto que os excertos sugerem que os estudantes compreendem a aula prática como uma estratégia de ensino que pode auxiliar na 
aprendizagem.

A experimentação destaca a participação efetiva dos estudantes, que passam de observador e executor de tarefas, a investigador e elaborador de hipóteses (GALIAZZI; GONÇALVES; 2004). Quando a mesma é realizada de maneira bem elaborada e com objetivos claros são ferramentas pedagógicas importantes, dentro de um processo de organização do ensino que auxilia a aprendizagem (GALIAZZI. GONÇALVES, 2004; SANTOS, 2009) Como pode ser visto nos excertos dos estudantes quando dizem que “A aula foi de extrema importância para compreendermos o efeito da alelopatia por meio dos resultados obtidos no experimento" (L24, A2); "Aprendi com os resultados da aula prática a ação dos extratos na germinação de sementes" (L6,A2); "Foi extremamente importante observar os resultados da aula prática, o que facilitou o entendimento da realização do experimento" (L25, A2).

Desse modo, Almeida (2001) evidencia que as atividades experimentais não se restringem apenas a experimentação e observação, mas envolvem especulações teóricas, o debate e a confrontação de ideias que contribuem par ao crescimento de estudante, "não há uma metodologia específica, bem definida, mas uma multiplicidade de métodos e processos a selecionar atendendo aos objetivos a atingir, aos conteúdos científicos em jogo, e ao contexto de aprendizagem" (ALMEIDA, 2001, p.59).

Em concordância, Suart e Marcondes (2004) destacam que se o estudante tiver a oportunidade de acompanhar e interpretar as etapas da investigação, ele possivelmente será capaz de elaborar hipóteses, testá-las e discuti-las, aprendendo sobre os fenômenos estudados e os conceitos que os explicam sendo possível alcançar os objetivos de uma aula experimental, que é o desenvolvimento de habilidades cognitivas e o raciocínio lógico.

Os resultados expostos pelos licenciandos demostram que a utilização da experimentação científica, é importante não apenas para motivar os estudantes e gerar momentos de aprendizagem, mas também para gerar mobilização dos saberes dos professores em formação inicial.

Por meio da aplicação do experimento os estudantes mobilizaram seus saberes disciplinares, apresentados nas aulas anteriores, os saberes pedagógicos a partir de uma aula baseada em uma modalidade didática diferentes das aulas expositivas, e por meio das experiências vividas durante a atividade, pôde proporcionar a construção dos saberes experienciais.

Para Pimenta (2012); Gauthier et al., (2013); Tardif (2014), esses saberes são primordiais para prática docente, pois auxiliam os professores a lidarem com as condições expostas em sua realidade de ensino.

Utilizar diferentes estratégias para o ensino na formação de professores se faz necessário para construção dos saberes docente. Visto que essa mobilização fica evidente, temos indícios que esses professores em formação possivelmente possuirão premissas para preparar aulas a partir de estratégias diferenciadas.

\section{Conclusão}

Foi possível evidenciar a influência positiva da utilização de atividade experimental na motivação dos estudantes, essa motivação é importante para gerar momentos de aprendizagem dos conteúdos. Foi possível verificar que houve uma melhor compreensão do conteúdo, uma vez que os estudantes participaram de todo processo de montagem e análise do experimento.

Além disso, os excertos textuais apontaram que a experimentação contribui na melhor compreensão do conteúdo teórico e agregou conhecimentos, além de desenvolver habilidades cognitivas e raciocínio lógico.

As atividades experimentais são importantes na formação dos professores de Ciências e Biologia, pois auxilia esses futuros professores a refletir, elaborar e concretizar estratégias para a realização do componente experimental de modo a desenvolver as capacidades científicas dos seus futuros alunos.

Assim, além de demostrar a importância da experimentação na formação inicial, um das possibilidades desse estudo é motivar pesquisadores da área a voltar suas pesquisas para formação inicial ou continuada de professores, a fim de prepará-los para atuarem em sua prática pedagógica com postura de pesquisadores e utilizar diversas estratégias didáticas no ensino de conteúdos de Biologia e Ciências.

\section{Referências}

ALMEIDA, A.M.F.G. Educação em ciências e trabalho experimental: Emergência de uma nova concepção. In VERÍSSIMO, A.; PEDROSA, A.; RIBEIRO, R. Ensino Experimental das Ciências: (re)pensar o ensino das ciências. Porto: Ministério da Educação de Portugal, 2001. p.51-73.

ARAÚJO, M.P. et al. As atividades experimentais como proposta na abordagem contextualizada dos conteúdos de biologia. In: ENCONTRO NACIONAL DE PESQUISA EM EDUCAÇÃO EM CIÊNCIAS E O I CONGRESSO IBEROAMERICANO DE INVESTIGAÇÃO EM ENSEÑANZA DE LAS CIÊNCIAS, 2011, Campinas, Anais..., Campinas: Unicamp, SP, 2011, p.1-12.

BARBOSA, B.S.S. Geometria não euclidiana de curvatura positiva: uma proposta de sequência didática. Cornélio Procópio: Universidade Estadual do Norte do Paraná, 2017.

DELIZOICOV, D.; ANGOTTI, J.A.P.; PERNAMBUCO, M.M.C. A. Ensino de ciências: fundamentos e métodos. São Paulo: Cortez, 2009.

FALA, A.M.; CORREIA. E.M.; PEREIRA. H.D.M. Atividades práticas no ensino médio: uma abordagem experimental para aulas de genética. Ciênc. Cognição, v.15, n.1, p.137-154, 2010.

FERREIRA, A.G.; BORGHETTI, F. Germinação: do básico ao aplicado. Porto Alegre: Artmed, 2004.

GALIAZZI, M.C.; GONCALVES, F.P. A natureza pedagógica da experimentação: uma pesquisa na licenciatura em química. Quím. Nova, v.27, n.2, p.326-331, 2004. doi: http://dx.doi.org/10.1590/ s0100-40422004000200027. 
GAUTHIER, C. et al. Por uma teoria da pedagogia: pesquisas contemporâneas sobre o saber docente. Ijuí: Unijuí, 2013.

GUERRA, I.C. Pesquisa qualitativa e análise de conteúdo: sentido e formas de uso. Portugal: Principia Editora, 2006.

KRASILCHIK, M. Prática de ensino de biologia. São Paulo: USP, 2004.

MARANDINO, M.; SELLES, S.E.; FERREIRA, M.S. Ensino de Biologia: histórias e práticas em diferentes espaços educativos. São Paulo: Cortez, 2009.

MORAES, R. Uma tempestade de luz: a compreensão possibilitada pela análise textual discursiva. Ciênc. Educ., v.9, n.2, p.191-211, 2003.

MORAES, R.; GALIAZZI, M.C. Análise textual discursiva. Ijuí; Unijuí, 2014

OLIVEIRA, J.R.S. Contribuições e abordagens das atividades experimentais no ensino de ciências: reunindo elementos para a prática docente. Acta Scie., v.2, n.1, p.139-153, 2010.

PIMENTA, S.G. Formação de professores: Identidade e saberes da docência. In: PIMENTA, S.G. (Org.). Saberes pedagógicos e atividade docente. São Paulo: Cortez, 2012. p.15-38.
PIRES, A. De quelques enjeux épistémologiques d'úne methodologie générale pour lês sciences sociales. In: DANS POUPART, J. et al. La recherche qualitative, enjeux épistémologiques et méthodologiques. Canadá: Gaëtan Morin, 1997.

SANTOS, A.B.A física no Ensino Médio: motivação e cidadania. Rev. Em Extensão, v.8, n.1, 2009.

SUART, R.C.; MARCONDES, M.E.R. A manifestação de habilidades cognitivas em atividades experimentais investigativas no ensino médio de Química. Ciênc. Cognição, v.14, n.1, p.50-74, 2009.

TAIZ, L.; ZEIGER, E. Fisiologia vegetal. Porto Alegre: Artmed, 2015.

TARDIF, M. Saberes docentes e formação profissional. Petrópolis: Vozes, 2014.

THOMAZ, M.F. A experimentação e a formação de professores de ciências: uma reflexão. Cad. Bras. Ensino Fís., v.3, n.17, p.360-369, 2010.

VIEIRA, V.; BIANCONI, M.L.; DIAS, M. Espaços não-formais de ensino e o currículo de ciências. Cienc. Cult., v.57, n.4, p.2123, 2005. 